\title{
PRODUÇÃO DA ARQUITETURA BANCÁRIA EM PRESIDENTE PRUDENTE-SP
}

Eduardo Guimarães Périco, Flórian Alonso, Lana Mika Ota, Natalia Catarine Tomé Marcondes, Mônica lamashita, Fabrícia Dias da Cunha de Moraes Fernandes Borges

Universidade do Oeste Paulista - UNOESTE. Curso de Arquitetura e Urbanismo, Presidente Prudente - SP.

\section{RESUMO}

Esta pesquisa tem por objetivo o levantamento arquitetônico e histórico dos antigos edifícios bancários localizados no quadrilátero central da cidade de Presidente Prudente, no interior do estado de São Paulo. Tais edifícios apresentam grande importância histórica por marcarem a presença da Arquitetura Paulista moderna na cidade. Por abordar o contexto histórico e cultural de Presidente Prudente, tal pesquisa subsidiará o embasamento para o desenvolvimento de inventário de bens culturais, além de servir de base para a realização de estudos adicionais em diferentes contextos, abrangendo aspectos ligados a produção arquitetônica brasileira assim como a preservação de tais bens. Serão realizadas pesquisas bibliográficas, bem como visitas in loco e consultas documentais.

Palavras-chave: arquitetura moderna, arquitetura bancária, Presidente Prudente, modernismo, movimento moderno brasileiro.

\section{PRODUCTION OF BANK ARCHITECTURE IN PRESIDENTE PRUDENTE}

\begin{abstract}
This research has as its goal the architectural lifting and historical of banking ancient buildings located on the central quadrilateral of the city of Presidente Prudente, in the inner of the State of São Paulo. These buildings present huge historical importance to mark the presence of Paulista modern architecture in the city. To board the historical and cultural context of Presidente Prudente, such research will subsidize the basement to the development of the inventory of cultural goods, besides serve as a basis for further studies in different context, including aspects connected to the Brazilian architectural production as well as the preservation of these goods. Bibliographic researches will be performed as well as in loco visits and documents consults.

Keywords: modern architecture, banking architecture, Presidente Prudente, modernism, Brazilian modern movement.
\end{abstract}




\section{INTRODUÇÃO}

O movimento moderno no Brasil surgiu a partir dos anos 30, é caracterizado como um dos pontos altos da arquitetura brasileira. Inserindo os fatos históricos numa linha do tempo, pode-se dizer que se iniciou em 1936 com a consultoria de Le Corbusier no prédio do Ministério da Educação e Saúde, sendo posteriormente propagado pelas ações da Política de Boa Vizinhança (1940-45), chegando à maturidade no projeto de Pampulha (1942-43). Finalmente, o ápice e o encerramento do seu ciclo ocorreram na construção de Brasília (1956-60) (CAVALCANTI, 2006).

As justificativas da ampla propagação deste movimento apresentam-se de cunho fortemente social. Caracteriza-se pela exclusão de adereços, ornamento, rompimento com elos do passado, estrutura aparente e a reprodução industrial que mostrou possível a produção de casas operárias em larga escala, ou seja, a asserção de projetos de moradias econômicas para a implantação de uma política de habitação popular (CAVALCANTI, 2006).

Dentro do modernismo, surge a partir dos arquitetos modernos de São Paulo, o movimento Brutalista Paulista, que teve seu auge em 1960. Segundo Zein, o Brutalismo possuía as características partidárias como a solução volumétrica de monobloco, atendendo todas as funções programáticas, quanto à composição, adota-se vãos completamente livres, tornando a organização dos espaços internos flexível, quanto a elevação jogo de volumetria (cheios e vazios), com aberturas protegidas que favoreçam a iluminação natural, quanto ao sistema construtivo, priorizam a verdade dos materiais e a honestidade estrutural. Sanvitto (2013) afirma que o Brutalismo defendia um posicionamento ético de favorecimento social, utilizando espaços únicos sugerindo a vida comunitária, como cita Artigas (1964) sobre o seu projeto para o Edifício da FAU USP:

Pensei que este espaço fosse a expressão da democracia. Pensei que o homem na Faculdade de Arquitetura teria o viço e que nenhuma atividade aqui seria ilícita, que não teria de ser vista por ninguém, e que os espaços teriam uma dignidade de tal ordem que eu não podia pôr uma porta de entrada, porque era para mim um crime. ${ }^{1}$

No Estado de São Paulo, o progresso da urbanização e da indústria acarretou em alterações na organização das áreas centrais e na dinâmica social. Os edifícios antigos, característicos dos períodos e estilos arquitetônicos anteriores, foram substituídos por prédios novos e modernos, pois as construções antigas já não atendiam as necessidades do período ou talvez porque não há vontade em readequá-los para a nova realidade (HIRAO, 2000).

Sendo assim, entre o período de 1930 e 1960 o Brasil é atingido por uma revolução estética na construção como um reflexo do clima de desenvolvimento que cobre o país. Fazer uso do 
moderno simbolizava estar em sincronia com o novo, o progresso e o avanço da nação. Por estas razões o estilo foi se propagando pelo país, sendo usado principalmente em estabelecimentos comerciais, além dos institucionais, para impor notoriedade. Dentre estes estabelecimentos notase a presença das agências bancárias.

\section{METODOLOGIA}

Relacionar a arquitetura moderna do Brasil com os estudos realizados no contexto local dos edifícios através de análises de projeto, pesquisas bibliográficas em periódicos e artigos científicos, levantamentos fotográficos e consulta a órgãos públicos.

\section{A ARQUITETURA BANCÁRIA}

Os setores financeiros do Brasil obtiveram um ganho significativo devido às mudanças econômicas que o país sofreu a partir de 1964. Várias leis e decretos transformaram a relação entre os bancos e os setores da sociedade. Como consequência os números de setores bancários se multiplicaram sendo transformadas em "pontos de venda" de dinheiro externo.

Com todo o avanço no setor bancário, as agências se sentiram na obrigação de reescrever a política mercadológica das instituições. O período requisitava locais mais atrativos e arquitetonicamente intensos. Assim, os setores passaram a se firmar em localidades que atraíssem maior atenção do público como nas regiões centrais, e passaram a adotar um estilo arquitetônico próprio. Este estilo passou a ser conhecido e intitulado pelos críticos de "arquitetura bancária" (STROHER, 1999).

A Arquitetura Bancária se rompeu em vários segmentos e caracterizou-se por refletir o término da linguagem modernista no país buscando novas alternativas e possibilidades formais para sua expressão. Assim como o modernismo, esta arquitetura vinha em oposição à hegemonia do período moderno clássico.

A produção destas obras marcou, e ainda marca, a paisagem dos centros urbanos devido a excepcionalidade dos prédios e a relação que os mesmos exerciam sobre o contexto pré-existente. Muitas são as cidades que fazem parte deste cenário, dentre elas está a cidade do interior do estado de São Paulo que está inserida no escopo desta pesquisa, Presidente Prudente. 


\section{A ARQUITETURA BANCÁRIA E PRESIDENTE PRUDENTE}

Conforme mencionado na introdução, o centro da cidade de Presidente Prudente não foi diferente das demais do estado de São Paulo. Vários casarios antigos foram substituídos por edifícios públicos e privados que buscavam, em sua devida época, por modernidade. Muitos destes foram projetados por discípulos e alunos de Artigas, sendo muitas delas agências bancárias construídas a partir de 1960 (HIRAO, 2008).

Neste trabalho, seis instituições bancárias localizadas no centro de Presidente Prudente SP serão objetos de estudo, as quais exibem características próprias do Modernismo e por isso, exibem contraste entre estes edifícios bancários e o entorno.

As Figuras 1 e 2 apresentam, respectivamente, um mapa e um quadro explicativo localizando os edifícios bancários modernistas.

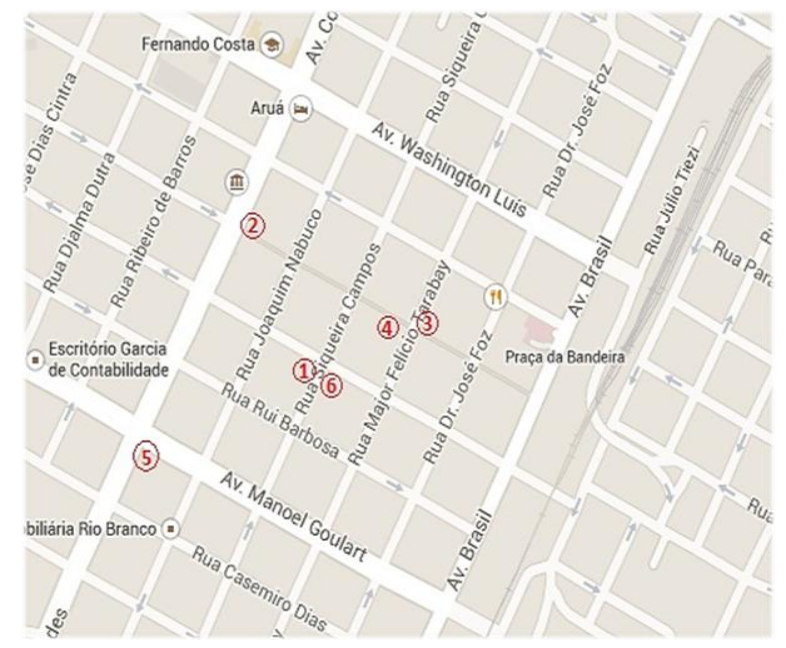

Figura 1. Localização dos edifícios bancários de aspectos modernistas no centro de Presidente Prudente

FONTE: Google Maps com alteração dos autores, 2014. 


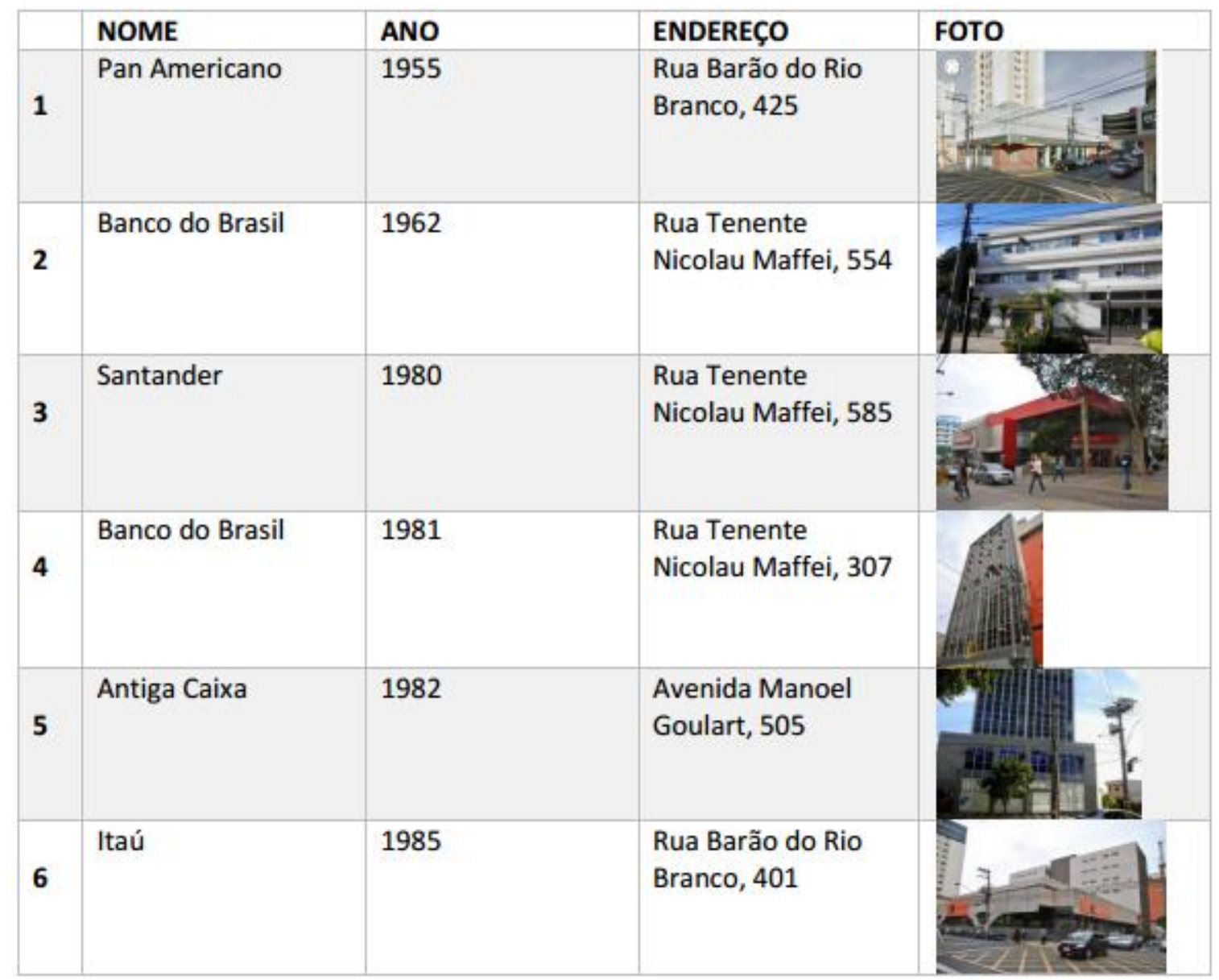

Figura 2. Quadro com informações dos edifícios bancários do quadrilátero central de Presidente Prudente

FONTE: Elaborado pelos autores, 2014

\section{CONSIDERAÇÕES FINAIS}

Em consulta a prefeitura do município foi possível ter acesso a aprovações dos projetos do Banco Santander (Rua Tenente Nicolau Maffei, 585) e do Banco do Brasil (Rua Tenente Nicolau Maffei, 307).

Analisando as características em comum dos bancos, foi observado o uso dos preceitos modernistas da arquitetura como planta livre, um dos elementos dos cinco pontos modernos instaurados pelo arquiteto franco-suíço Le Corbuiser, que possibilita o uso dos espaços internos de uma forma mais diversificada, e a flexibilidade na articulação.

Segunda Maria Luiza Sanvitto, o Brutalismo Paulista possui característica como a composição univolumétrica, que é evidente no banco Santander, um monobloco com subtração, assim como o banco do Brasil, fachada principal do edifício possui a forma retangular e a oposta a este sofreu uma subtração, que fica evidente nas fachadas laterais. 
A verdade dos materiais e das estruturas, como em ambos os edifícios de estudos, destacam o concreto aparente, o vidro, no Santander destaca-se o uso de brises, iluminação zenital e pilares.

Portanto, pelos estudos iniciais observa-se que é notória a presença das características da Escola Brutalista Paulista, em ambas as obras em estudo, porem como instituições bancárias muitas vezes necessitavam seguir uma padronização de suas identidades estética, marketing e mercadológica, os aspectos da filiação estilística Brutalista aparecem de maneira mais suavizadas e assim, conseguem contemplar as recomendações técnicas e padronização das instituições, ao mesmo tempo que propugnavam a essência da corrente paulista.

\section{REFERÊNCIAS}

ARTIGAS, João Batista Vilanova. A Função Social do Arquiteto. São Paulo, Nobel, 1989.

CASTRIOTA, Leonardo. Arquitetura da Modernidade. Belo Horizonte: Instituto de Arquitetos do Brasil- Editora UFMG/IAB-MG, 1998.

CAVALCANTI, L. Moderno e Brasileiro: a história de uma nova linguagem na arquitectura (193060). 2006.

HIRAO, H. Arquitetura Moderna Paulista, imaginário social urbano, uso e apropriação do espaço. [2000]. Disponível em < http://www.docomomo.org.br/seminario\%208\%20pdfs/051.pdf>. Acesso em 02 Abr. 2014.

HIRAO, H. Arquitetura moderna em Presidente Prudente e o imaginário social urbano. Presidente Prudente, 2008.

HIRAO, H. Um olhar multidisciplinar sobre a forma da área central de Presidente Prudente. [2000].

SEGAWA, H. Arquitetura no Brasil 1900-1990. 2 ed. São Paulo: Editora da USP, 2002.

STROHER, R. A. As transformações na tipologia e no caráter do prédio bancário em meados deste século. Dissertação (Mestrado em Arquitetura). Universidade Federal do Rio Grande do Sul. Porto Alegre, Maio $\quad$ de $1999 . \quad$ Disponível em <http://www.lume.ufrgs.br/bitstream/handle/10183/70359/000249875.pdf?sequence=1>. Acesso em 02 Abr. 2014.>. Acesso em 02 Abr. 2014.

SANVITTO, M. L. A. Brutalismo Paulista: uma estética justificada por uma ética? X SEMINÁRIO DOCOMOMO BRASIL ARQUITETURA MODERNA E INTERNACIONAL: conexões brutalistas 1955-75 Curitiba. 15-18.out.2013 - PUCPR. Universidade Federal do Rio Grande do Sul. Disponível em $<$ http://www.xdocomomo brasil.com.br/download/artigos/conexoes/CON_03.pdf>. Acesso em 05 Agos. 2014. 
ZEIN, R, V. A arquitetura da escola paulista brutalista 1953-1973. (Doutorado). Universidade Federal do Rio Grande do Sul. Faculdade de Arquitetura. Programa de Pesquisa e Pós-Graduação em Arquitetura. Disponível em <http://www.lume.ufrgs.br /handle/10183/5452> Acesso em 31 Jul. 2014. 